\title{
O impacto da pandemia provocado pelo coronavírus no cenário educacional brasileiro
}

\author{
The impact of pandemia caused by the coronavirus in the brazilian \\ educational scenario
}

RAQUEL TORCANI CARMONA

Pontificia Universidade Católica de São Paulo-PUCSP

RESUmo O presente artigo busca apontar, ainda que de forma sucinta, alguns entre os vários efeitos da pandemia provocada pela disseminação da Covid-19 e que impactaram o cenário educacional brasileiro. É bem verdade que não se pode, ao menos com bases seguras, prever o que ainda está por vir, todavia já é possível realizar um diagnóstico, mesmo que parcial, desses efeitos. Os problemas estão longe de terminar, mesmo assim, quanto mais incisivo e precoce é o debate, tanto maior serão as chances de se alcançar soluções possíveis e mais factíveis em tempo menor. Para tanto, propomos algumas reflexões, sem deixar de avaliar a necessidade de soluções, pois em nosso modo de discernir, elucubrações não são capazes de conduzir o ser humano a resultados efetivos e o problema da educação no Brasil é algo que requer soluções urgentes.

Palavras-chave: Covid-19. Educação. Medidas sanitárias. Direitos fundamentais.

\begin{abstract}
This article seeks to point out, albeit succinctly, some of the various effects of the pandemic caused by the spread of Covid-19 and which impacted the Brazilian educational scenario, it is true that it is not possible, at least on a secure basis, to predict the that is yet to come, however it is already possible to make a diagnosis, even if partial, of these effects. The problems are far from over, even so, the more incisive and early the debate, the greater the chances of reaching possible and more feasible solutions in less time. To this end, we propose some reflections, without failing to assess the need for solutions, because in our way of discerning, clarifications are not able to lead human beings to effective results and the problem of education in Brazil is something that requires urgent solutions.
\end{abstract}

Keywords: Covid-19. Education. Health measures. Fundamental rights.

\section{INTRODUÇão}

A segunda década deste século (2020) foi marcada, e entrará para a cronologia da humanidade, pela inesperada proliferação de um inimigo minúsculo e invisível identificado 
como coronavírus SARS-CoV-2, micro-organismo que apresenta um quadro clínico que varia de infecções assintomáticas a implicações respiratórias graves, cujo grau de letalidade é extremamente elevado. Os estragos resultantes da pandemia ensejada por esse vírus, atualmente, ainda não podem ser mensurados, e as consequências ainda serão irradiadas por um período bastante extenso.

Vale destacar que essa temática servirá, ainda, de matéria-prima para alimentar inúmeros debates em todas as áreas do conhecimento humano contemporâneo. No entanto, nossa contribuição, neste artigo, se restringe a realizar algumas reflexões, embora singelas, dos impactos provocados pela pandemia da Covid-19 no contexto educacional. Não pretendemos realizar uma abordagem multifacetada, mas apenas destacar o agravamento das condições na oferta do ensino do cenário brasileiro em todos os níveis e contextos sociais.

O ensino público brasileiro, há décadas, vem sendo submetido ao constante processo de sucateamento. Os governos mudam periodicamente, em precisa obediência ao princípio democrático, contudo nenhum deles se mostrou, até hoje, capaz de resolver, ou ao menos, mitigar de forma satisfatória os problemas da educação brasileira que se tornaram crônicos.

A pandemia que também acometeu o Brasil notabilizou as desigualdades sociais, acentuando-as, e também tornou ainda mais evidentes as dificuldades enfrentadas pela parcela mais vulnerável da população, que o grupo mais abastado da sociedade insiste em ignorar.

Em nenhum momento da história brasileira o sistema educacional foi tão ultrajado, seja pela dificuldade de acesso ao conhecimento por quem não possui recursos materiais e tecnológicos, ou pelo caráter assistencial que a escola, de alguma forma, também desempenha. Tomemos como exemplo a permanência das crianças de escolas públicas e privadas, como alternativa para pais que trabalham e não têm com quem deixar os filhos pequenos, ou mesmo no caso das populações de regiões periféricas e pobres, onde as crianças frequentam a escola, não tendo como foco principal o enriquecimento intelectual, mas como forma de garantir as refeições diárias que não encontram em casa.

O fechamento dos estabelecimentos de ensino, como medida sanitária de combate ao avanço viral, trouxe problemas de toda ordem. O isolamento também impôs aos pais o acompanhamento das aulas dos filhos, que passou a ser realizado a distância, inserindo a prática do homescholing (educação domiciliar).

São muitas situações que provocam sistemáticas inquietações tanto para aqueles que atuam, quanto naqueles que são destinatários de serviços do setor educacional. As angústias se acirraram ainda mais com a incidência da pandemia provocada pelo coronavírus, desolação, medo do futuro e instabilidade econômica. Todo esse caldo aponta para um futuro incerto e o cenário que se apresenta não oferece muitas esperanças no porvir.

\section{O CENÁRIO GERAL da COVID-19}

O Brasil foi um dos países mais afetados pelo avanço viral da Covid-19, acumulando números desoladores de vítimas em toda a sua extensão territorial. Todavia, é importante lembrar que o nosso sistema jurídico, especialmente a Carta Magna, traz alguns instrumentos para enfrentar situações excepcionais e perigosas, a exemplo da pandemia provocada pelo SARS-CoV-2. 
No caso da Covid-19, quando o vírus começou a se espalhar pela Europa, mas mesmo não havendo qualquer caso no Brasil, o Poder Executivo, representado pelo Ministério da Saúde, publicou a Portaria $n^{\circ}$. 188-20-MS, de 3 de fevereiro de 2020, declarando Emergência em Saúde Pública de Importância Nacional (ESPIN) em decorrência da infecção humana pelo Coronavírus (2019-nCoV). Até então, tratava-se apenas de perigo iminente de contágio e possível propagação do vírus.

Diante de dezenas de casos confirmados da doença, com alto índice de mortalidade, o presidente da República, com aprovação do Congresso Nacional, declarou estado de calamidade pública. Dessa forma, o Decreto Legislativo ${ }^{\circ}$. 6, de 2020, reconheceu para fins do artigo 65 da Lei Complementar $\mathrm{n}^{\circ}$. 1.010/2000 (Lei de Responsabilidade Fiscal), a superveniência do estado de calamidade pública. Essa providência é imprescindível para permitir que o Poder Executivo aumente os gastos e permaneça desobrigado de cumprir a meta fiscal anteriormente prevista, fundamentalmente no que se refere à disponibilização de recursos para Estados-membros e municípios, no enfrentamento da crise sanitária.

Na realidade, o debate acerca da responsabilidade do Estado seja por ação ou omissão traz consigo amplo campo de confrontação das diferentes teorias, sobretudo no que diz respeito à aplicação da teoria objetiva de responsabilização que, a cada dia, vem alcançando mais espaço no contexto jurídico brasileiro. Saliente-se, ainda, que o Estado tem poderes soberanos de polícia e de regulação.

A legislação especial para a regulação da pandemia de Covid-19 (que vem sendo alterada por medida provisória e regulada por atos administrativos) trouxe uma série de medidas de restrição à circulação de pessoas. Por exemplo, a restrição excepcional e temporária em portos ou aeroportos, para entrada e saída do país, e locomoção interestadual e intermunicipal. A normativa promove delegação a fatos, e irroga à ANVISA e às "evidências científicas" o fundamento para a prática do ato de autoridade excepcional.

Tais medidas, certamente, prejudicaram o setor econômico e empresarial, e ainda vão prejudicar muitas pessoas, que terão grande dificuldade de comprovar o prejuízo e receber alguma indenização compensatória. A regra na teoria geral dos seguros é a da repartição simples. Se todos sofrem dano não existe muito de onde tirar o valor da indenização, cada um acaba por suportar sua carga de prejuízo individual. Situações excepcionais terão tratamento diferenciado, mas o tempo se encarregará de aniquilar o direito que eventualmente possam ter. Pior ainda, quando se pretenda uma indenização dos cofres públicos.

Todos os cidadãos, indiscriminadamente, estão pagando a conta de alguma forma, nenhum brasileiro foi poupado das medidas restritivas, ou do pleno exercício da liberdade de ir e vir e da livre iniciativa. Há muito tempo a humanidade não vivenciava uma situação tão extremada.

O pós-pandemia aponta para uma nova realidade, novos hábitos e diferentes comportamentos sanitários. As relações humanas não serão mais as mesmas, os contratos de trabalho, os vínculos familiares, de amizade e a forma de aproximação entre as pessoas estão sendo, gradativamente, recompostos no mundo inteiro.

\section{OS DILEMAS DA EDUCAÇÃO BRASILEIRA}

As questões educacionais refletem as mazelas da própria sociedade. Entre os fatores que, seguramente, sabotam a existência de um cenário mais favorável para a educação está 
a pobreza, a fome, a falta de trabalho e falta de perspectiva. Na origem da precariedade na formação educacional intelectual do indivíduo, há uma família muito carente, material e intelectualmente.

Na segunda década do século XIX, o Brasil tornou-se independente com, praticamente, toda a população analfabeta. Foi Dom Pedro I quem introduziu o tema da instrução pública na Assembleia Constituinte de 1823, entretanto a Constituição do Império não garantia a todos os brasileiros o acesso à educação primária, posto que negros e escravos alforriados não eram considerados cidadãos.

A população, de maneira geral, nunca se envolve seriamente nas questões educacionais, não se tem notícia de qualquer engajamento mais substancial, e a população, protestando de forma veemente e agressiva, pleiteasse soluções definitivas. De modo diferente, por exemplo, quando há manifestações públicas ou greves buscando reajustes de salários, ou diminuição de tarifa de transporte, ou mesmo em função de posições políticas. Não há no inconsciente coletivo a legítima preocupação com os rumos que a educação brasileira, há tempos, vem tomando.

Nessa trilha, a situação fica cada vez pior, década após década, governo após governo, geração após geração. Os indivíduos não entendem que priorizar a pauta a educação resolveria muitos outros problemas, sem que houvesse necessidade de insurgir-se por outros motivos, pois a educação é anterior às questões políticas, já que envolve lucidez no processo de eleição dos representantes do povo.

Outra questão importante, sem desprezar tantas outras, é o fato de que mais da metade dos recursos do Ministério da Educação é aplicado no ensino superior, o que contraria a Constituição Federal vigente, que dá prioridade ao combate ao analfabetismo e ao ensino fundamental.

As prioridades do sistema educacional deveriam ser:

a) Diminuição dos índices de repetência e evasão nas escolas;

b) Investimento maciço e ampliação do acesso ao ensino básico, fundamental e médio; e

c) Melhoria das condições de ensino, incluindo formação e aperfeiçoamento de docentes, investimento em recursos tecnológicos e de infraestrutura.

Para que isso aconteça, é preciso atuar em várias frentes, melhorar a remuneração dos docentes levando em conta o desempenho, prestar assistência financeira ao estudante carente com alimentação completa e não apenas com a merenda escolar, material didático, equipamentos tecnológicos etc. A Administração Pública deve procurar manejar de forma mais eficiente possível os recursos disponíveis, privilegiando as regiões mais indigentes e dando apoio aos entes federativos (Estados, municípios e Distrito Federal), sem deixar de promover o necessário e rigoroso controle.

Com relação ao empenho do setor público no fomento ao ensino superior, existem duas explicações razoáveis, uma de natureza política e outra relacionada às necessidades do país. A primeira, leva em conta o fato de que a formação de nível universitário beneficia, principalmente, a imagem do Brasil perante a comunidade internacional, deixando para trás o 
rótulo de nação atrasada, rudimentar, de mentalidade colonial e escravocrata. A segunda hipótese, diz respeito mais diretamente às necessidades de desenvolvimento do país. O avanço tecnológico é crucial para a conformação de uma economia competitiva, exigindo recursos humanos altamente qualificados. Entretanto, a inserção do grande contingente populacional no ensino superior impactou negativamente na qualidade, porque coloca o indivíduo em bases sólidas de conhecimento em um ambiente mais avançado educativamente falando.

A precariedade do ensino básico, fundamental e médio, produz indivíduos despreparados, sem condições de absorver conhecimentos mais avançados, o que leva ao mau aproveitamento do conteúdo dispensado nos cursos de graduação. As instituições de ensino superior privadas, diante da ganância em obter lucro, em um mercado robusto e com um quadro de escassez imenso, promove a precarização de toda a cadeia do setor, cumprindo minimamente as exigências dos órgãos públicos, é a lógica para obter mais lucro, investir o mínimo para lucrar o máximo.

O crescimento econômico não envolve apenas a capacidade de utilizar tecnologias existentes, mas também adaptá-las e de promover inovações. Não é suficiente, para adquirir tal capacidade, a universalização da escolarização básica, embora ela seja indispensável. A formação científica em nível superior é igualmente importante. Para além desse raciocínio, também devemos considerar que o processo de desenvolvimento econômico e social também exige pessoas com qualificação e que tenham múltiplas competências, como aquelas necessárias para gerir corporações do setor privado e entidade do setor público.

A sociedade para se desenvolver precisa, ainda, de contingentes humanos capazes de elaborar as análises sobre os rumos da economia e as condições de vida, saúde e trabalho da população; avaliar as limitações do sistema educacional e as distorções do sistema político; articular e conhecer a dinâmica do movimento sindical; compreender fluxos migratórios e o processo de urbanização; avaliar o impacto da transformação socioeconômica no meio ambiente, e assim por diante.

Por essa razão é que qualquer projeto de modernização socioeconômica não pode prescindir de universidades capazes de desenvolver a pesquisa científica e formar profissionais mais qualificados. Esses elementos justificam a destinação de recursos públicos para a manutenção do ensino superior e não há qualquer equívoco nisso. A problemática se instaura quando se verifica que não há equilíbrio ou coerência na distribuição dos recursos que, por ser insuficientes, priorizam a educação superior em detrimento da formação básica e profissional.

\section{4.) O ENQUADRAMENTO DA EDUCAÇÃO NO ROL DE DIREITOS SOCIAIS}

Se, de um lado, os direitos individuais servem ao fim de proporcionar liberdade ao indivíduo, limitando a atividade coercitiva do Estado, os direitos sociais, de outro, visam assegurar uma compensação das desigualdades fáticas entre as pessoas, que apesar de pertencerem a sociedades complexas, "possuam prerrogativas que os façam reconhecer-se como membros igualitários de uma mesma organização política” (AGRA, 2010, p. 516-517).

Na mesma análise, destacamos que se, de uma parte os direitos privativos de cada um servem para aparelhar os indivíduos de liberdade, impondo fronteiras à atividade coercitiva 
do Estado, de outra parte, os direitos sociais buscam assegurar um equilíbrio das desigualdades materiais entre as criaturas, que muito embora façam parte de uma sociedade complexa, [...] possuam prerrogativas que os façam reconhecer-se como membros igualitários de uma mesma organização política (AGRA, 2010, p. 516-517).

A Constituição Federal de 1937 implantou a ditadura do Estado Novo. Os poderes Executivo e Legislativo encontravam-se concentrados no presidente da República, que legislava via decretos-lei e posteriormente os aplicava. Sobre a educação, essa Constituição representou retrocesso em relação à anterior (1934). A vinculação obrigatória de recursos para a pasta foi extinta e, embora fosse obrigatório e gratuito o ensino primário, mas dos menos necessitados era exigida uma contribuição mensal para a caixa escolar, como uma forma de solidarizar o custo social.

Em 1964, o Brasil sofreu uma dura e terrível investida, foi instaurada a ditadura militar que permaneceu vigente até início dos anos 1980. Durante esse período, vigorou a Constituição de 1967, que perseguiu a ideia de institucionalizar o regime militar, outorgando ao Executivo mais poder de decisão, e influenciando fortemente o Legislativo e o Judiciário. Essa Constituição manteve a estrutura organizacional da educação nacional, preservando os sistemas de ensino dos Estados.

Seguindo a mesma linha do texto constitucional anterior (CRFB-1946), a Constituição de 1967 manteve a estrutura organizacional da educação nacional, preservando os sistemas de ensino dos Estados. Entretanto, destacamos os seguintes aspectos negativos, que representaram um intenso retrocesso, acentuando ainda mais o atraso nacional:

a) o fortalecimento do ensino particular, inclusive mediante previsão de substituição do ensino oficial gratuito por bolsas de estudo;

b) a necessidade de bom desempenho para garantia da gratuidade do ensino médio e superior aos que comprovarem insuficiência de recursos;

c) a limitação da liberdade acadêmica pela fobia subversiva;

d) a diminuição do percentual de receitas vinculadas para a manutenção e desenvolvimento do ensino limitadas somente aos municípios após 1969.

Vejamos:

Artigo 176 - A educação, inspirada no princípio da unidade nacional e nos ideais de liberdade e solidariedade humana, é direito de todos e dever do Estado, e será dada no lar e na escola.

$[\ldots]$

$\S 3^{\circ}$. A legislação do ensino adotará os seguintes princípios e normas:

II - o ensino primário é obrigatório para todos, dos sete aos quatorze anos, e gratuito nos estabelecimentos oficiais;

III - o ensino público será igualmente gratuito para quantos, no nível médio e no superior, demonstrarem efetivo aproveitamento e provarem falta ou insuficiência de recursos;

IV - o Poder Público substituirá, gradativamente, o regime de gratuidade no ensino médio e no superior pelo sistema de concessão de bolsas de estudos, mediante restituição, que a lei regulará.

$[\ldots]$ 
Mais recentemente, a Carta Constitucional promulgada em 5 de outubro de 1988 estabeleceu o Estado Democrático de Direito, também nomeada de "Constituição Cidadã", por ter ampliado o rol dos direitos sociais, entre os quais se inserem o direito à educação e as atribuições do poder público.

De fato, a Constituição de 1988 foi bastante enfática na promoção, universalidade e acesso indiscriminado da população à educação, pois essa constitui eficiente mecanismo de ação política. Foram dedicados à educação os artigos 202 a 214 da seção I do capítulo III - Da Educação, Da Cultura e Do Desporto, do título VIII - Da Ordem Social.

Nota-se, portanto, a importância dada pelo legislador à matéria. O legislador constituinte promoveu um grande avanço em termos de qualidade comparativamente às normas jurídicas anteriores, uma vez que a declaração do direito à educação está muito bem detalhada, com clareza e precisão da redação, incluindo até mesmo os mecanismos jurídicos de garantia para a fruição do referido direito.

No caso da garantia efetiva desse direito, o sujeito passivo é o Estado e a família. O Poder Público tem a responsabilidade de criar políticas públicas garantindo o acesso de todos à educação, conforme consta no artigo 206 do texto constitucional, e por disposição evidente, o Estado fica obrigado a fornecer o ensino fundamental gratuito, nos termos do artigo 208, $\S 1^{\circ}$. Já a família que é a guardiã dos interesses das crianças em tenra idade deve garantir o ingresso, a frequência e a permanência dos alunos nos estabelecimentos de ensino públicos ou privados.

Para que o direito à educação seja plenamente realizado, o seu conteúdo deve integrar as disposições constitucionais e ser previsto nas leis e nas políticas. Além disso, é necessário que devam existir mecanismos para executá-lo, o que inclui a possibilidade de o direito à educação ser sujeito à jurisdição. Isso significa que "o direito à educação não é um ideal ou uma aspiração, mas um direito legalmente executável”, e isto indica que o sistema judicial possui um papel essencial em protegê-lo e salvaguardá-lo.

Para Norberto Bobbio, em sua célebre obra "A era dos direitos", na afirmação e no reconhecimento dos direitos políticos e sociais, só de modo genérico e retórico se pode afirmar que todos são iguais. Sobretudo, com relação aos três direitos sociais fundamentais (ao trabalho, à instrução e à saúde); ao contrário, é possível dizer, realisticamente, que todos são iguais no gozo das liberdades negativas (BOBBIO, 1992).

Hannah Arendt (1989, p. 300-336), ao tratar dos regimes totalitários, destaca que todos esses foram ancorados na generalizada e intolerável rejeição de determinados grupos ou classes sociais, e resultou uma inédita ruptura com o legado dos direitos humanos e com a própria tradição do pensamento jurídico.

Observe que o totalitarismo se constitui por um regime político estruturado no controle total da vida das pessoas pelo Estado, no nacionalismo exacerbado e no intenso militarismo, que foi implementado em alguns países da Europa no século XX.

É nesse cenário que o pós-Guerra significou a sua reconstrução, fazendo prevalecer na ordem internacional, com efeito direto no plano interno das comunidades nacionais, o referencial axiológico dos direitos humanos (COMPARATO, 2010).

Buscando um contraponto, notamos que por outro viés, Ana Paula de Barcellos procura delimitar o conteúdo do mínimo existencial segundo a realidade brasileira. De 
acordo com sua convicção, o mínimo existencial inclui o direito à educação fundamental como parte do mínimo existencial, direito à saúde, assistência aos desamparados e o acesso à Justiça (BARCELLOS, 2019).

\section{IMPACTOS DA PANDEMIA NO SISTEMA EDUCACIONAL}

Nem todos os impactos suportados pelo setor educacional público ou privado foram negativos. Por óbvio que as medidas impostas pelas autoridades governamentais criaram dificuldades de várias ordens, principalmente para aqueles que já enfrentavam obstáculos quanto ao acesso às instalações, ou ainda indisponibilidade de equipamentos tecnológicos para acessar as aulas de forma remota, procedimento adotado por várias escolas. Os mais vulneráveis foram aqueles que mais sofreram, por exemplo, moradores de comunidades rurais e regiões da periferia ou suburbanas.

Forçosamente, do dia para a noite, todos precisaram se adaptar ao novo modelo de ensino-aprendizagem, o ensino remoto. Aqueles que não simpatizavam com o computador ou enxergavam no telefone celular apenas um artefato para falar com outras pessoas distantes, sem estar preso a fios e cabeamentos, foram os que mais se incomodaram, ou se desacomodaram.

O lado positivo está no fato de que essas pessoas, mais conservadoras e tradicionalistas, resistentes às inovações, foram literalmente "atiradas ao mar" da tecnologia, ou seja, submergindo no oceano da nova era.

Outro fato que também merece ser destacado diz respeito aos vínculos familiares, as pessoas foram obrigadas a conviver com seu núcleo familiar mais próximo, compulsoriamente, levando as pessoas a revisitar seu próprio modo de vida. A pandemia obrigou os pais a acompanhar o desempenho escolar dos filhos, por meio das aulas remotas e contatos frequentes com os professores. A participação da família na formação das crianças estava se tornando um problema de grandes proporções, na medida em que afastados da supervisão dos pais, na fase mais delicada da vida, os jovens acabavam se envolvendo com drogas ou atos ilícitos de várias ordens.

Não podemos deixar de destacar que por meio da educação também se combate doenças e moléstias perniciosas. A compreensão da causalidade é essencial à busca de respostas sobre as possibilidades de prevenir a doença. De evitar que ela se instale. Dada a natureza dos fatores envolvidos, vê-se que, diante de alguns deles, não se pode interferir. É o caso dos marcadores genéticos de sexo, por exemplo, que determinam a vulnerabilidade das mulheres a câncer de útero ou de homens a câncer de próstata, especificidades de cada sexo.

Também pouco se pode fazer, pelo menos em curto prazo e em dimensão individual, a respeito de determinados fatores ambientais já identificados como correlacionados a algumas patologias: poluição ambiental, irradiações, agrotóxicos etc. Compreender e controlar doenças requer conhecimento científico e experiências que vão desde a análise dos complexos mecanismos de regulação molecular intracelular até as escolhas individuais de estilos de vida. 


\section{SoluÇões POSSíVEIS PaRa O ALCANCE de UMA EDUCAÇÃo de QUALIDAde}

Do ponto de vista social, as comunidades que possuem um contingente populacional com elevado grau de escolaridade também alcançam índices de produtividade superiores, gerando mais riquezas e, por conseguinte, proporcionando melhor qualidade de vida para os seus membros, uma vez que dispõem de mais recursos. Além da positividade do aspecto econômico, a qualificação profissional mais arrojada contribui para uma sociedade municiada de cidadãos mais conscientes de suas obrigações cívicas, assim como estarão mais preparados para a prevenção de doenças e acidentes, interessados em assuntos relacionados à política e menos influenciados ou seduzidos por atividades ilícitas.

Saliente-se que a Constituição Federal de 1988, na euforia causada pelo fim do regime ditatorial e a restauração da democracia, elaborou um amplo rol de direitos fundamentais de segunda geração ou dimensão, mais precisamente aqueles constantes do artigo $6^{\circ} .:$ educação, saúde trabalho, moradia, lazer, segurança, previdência social, proteção à maternidade e à infância, alimentação, transporte, não excluindo a possibilidade de incluir-se outros vindouros.

$\mathrm{O}$ medo aterrorizante provocado pelos anos sob regime militar impulsionou o legislador constituinte à ânsia desmedida em constitucionalizar direitos antes ostensivamente negados. Como se trata de direitos fundamentais, sua aplicabilidade é imediata, e na hipótese de omissão legislativa, a própria Constituição oferece o mandado de injunção e a ação direta de inconstitucionalidade por omissão, como meios de buscar sua concretização.

Não há como negar que os direitos sociais exigem a atuação do Estado para a sua efetivação. Sob essa perspectiva, a pessoa é posta para além da sua condição individual, é uma relação que necessita para êxito de dois atores, o indivíduo e a sociedade.

De fato, os direitos sociais exigem a intermediação dos entes estatais para sua concretização e fazem isso por meio de políticas públicas; consideram o homem para além de sua condição individualista, e guardam íntima relação com o cidadão e a sociedade, porquanto abrangem a pessoa humana na perspectiva de que ela necessita de condições mínimas de subsistência. As políticas públicas são os conjuntos de programas, ações e decisões tomadas pelos governos (nacionais, estaduais ou municipais) com a participação, direta ou indireta, de entes públicos ou privados que visam assegurar determinado direito de cidadania para vários grupos da sociedade, mas não afasta a participação da sociedade na definição de tais políticas.

As pandemias, sabidamente, acabam quando mais da metade da população tenha tido contato com o vírus, e assim já esteja imunizada. Identificar esse momento de descida da curva de contaminação, por algum critério científico sério, é essencial para decidir sobre o momento do desconfinamento de pessoas (ou o fim das restrições de liberdade), mas mesmo com o afastamento dos riscos de contágio, a mudança de comportamentos no setor educacional tomou um caminho sem volta.

Apresentamos as ideias citadas para obviar nossas conclusões jurídicas, e não para exibir uma receita do que solucionaria o problema. Sabemos que os casos individuais da doença se mostram das mais variadas formas. De uma perspectiva do direito público, o importante é perceber que o vírus não é seletivo, mas a desigualdade sim. As mortes estão sim ocorrendo nas regiões mais pobres, onde as condições de atendimento e tratamento são piores (seja em casa, seja nos postos de saúde). 
As escolas públicas foram ótimas nos anos 50, até que os filhos da classe pobre puderam se matricular (contra a vontade da nobreza, é claro). Com a entrada dos mais humildes no ensino universal, os recursos do Estado migraram para outros setores (pois quem decide o destino das verbas não são os desvalidos). O mesmo se dá na área da saúde, e a pandemia de Coronavírus é apenas uma lente de aumento que clarifica a falta de isonomia no tratamento de casos e situações. Em matéria de cultura, ensino e saúde, sempre houve desigualdade de tratamento por parte do Estado: a diferença agora é que um caminho mal traçado na pandemia pode ser irreversível.

A procura e a manutenção de um padrão mínimo de qualidade definido nacionalmente, assim como a forma de buscar um investimento mínimo por aluno matriculado, são os critérios que norteiam a distribuição dos recursos alocados para educação e distribuídos entre os Estados e municípios.

Recentemente houve a aprovação do novo FUNDEB-Fundo Nacional de Desenvolvimento da Educação Básica, no Senado Federal, encerrou-se uma etapa muito importante na luta pela melhoria da qualidade do ensino básico, mas ainda há muito para fazer. Graças a essa medida, o Brasil passará a ter um mecanismo ainda mais forte de enfrentamento das desigualdades educacionais. O novo FUNDEB, mais redistributivo e com maior eficiência alocativa, é uma demonstração de que o esforço de vários grupos da sociedade é o único caminho para evoluir nesse setor. A partir de 2021, a educação básica brasileira, em especial os municípios mais pobres, terão mais recursos disponíveis para o enfrentamento dos enormes desafios rumo à garantia do direito de todas as crianças e jovens a um ensino de qualidade. $\mathrm{E}$ isso se faz ainda mais importante agora, com os brutais efeitos da pandemia na Educação.

\section{CONSIDERAÇões FINAIS}

Caminhando para o desfecho das nossas reflexões, concluímos que a participação da iniciativa privada na área da educação é garantida, mas marcada pelo caráter de suplementação à atuação estatal.

Seguramente, o mundo não será mais o mesmo depois dessa pandemia de proporções colossais jamais vistas na contemporaneidade. As transformações, tanto no campo do comportamento humano individual, quanto nas relações sociais, econômicas, culturais e jurídicas, por certo serão reacomodadas em todos os rincões planetários. entretanto concentremo-nos apenas no contexto brasileiro.

As profundas fissuras sociais impregnadas na realidade brasileira já foram exaustivamente esmiuçadas em diversos trabalhos acadêmicos, estatísticos, jornalísticos, literários e cinematográficos. As desigualdades sociais, a crise na educação, a deficiência na prestação dos serviços públicos, as adversidades na saúde pública, enfim, destacar tudo isso é mais do mesmo. Todavia, nunca ficou tão evidente a necessidade e a importância de investimentos robustos em educação e pesquisas científicas, evitando o aniquilamento da raça humana por doenças ainda desconhecidas, e também por via indireta resolveria, se não todas, mas boa parte de outros problemas sociais.

É verdade que a análise das normas constitucionais que tratam da educação revela a existência de direitos subjetivos, conferidos ao cidadão diretamente pela Constituição, ca- 
pazes de garantir sua oponibilidade ao Estado quando não implementados voluntariamente, por meio da tutela jurisdicional.

O desenvolvimento da humanidade está ancorado na crença de uma ciência capaz de trazer benefícios, controlando certos riscos. Contudo, a grande velocidade que a ciência evolui aumenta os riscos imprevisíveis. Dessa forma, um panorama duvidoso e de possibilidade da ocorrência de danos graves impõe a formação da teoria da precaução.

Não se pode olvidar que a sociedade é um organismo vivo que todos os dias é submetida às pequenas ou micromutações, que ao longo do tempo se aprofundam, transformando as feições e as características daquele grupo social. Nessa toada, o Direito precisa acompanhar essas mudanças, sob pena de se tornar obsoleto.

A justiça é um valor que a sociedade persegue desde priscas eras, e o Direito existe justamente para aproximar a sociedade mais perto possível desse valor. A justiça como pilar da sociedade desde sempre esteve presente na história grega antiga e, principalmente romana. A importância dessa concepção para os gregos pode ser verificada em seus textos filosóficos e poéticos que refletem não somente o interesse dos filósofos antigos pelo tema, mas principalmente pelo espaço que a justiça e a educação ocupavam nos assuntos públicos daquela época.

\section{REFERÊNCIAS}

AGRA, Walber de Moura. Tratado de Direito Constitucional, v. 1 / coordenadores Ives Gandra da Silva Martins, Gilmar Ferreira Mendes, Carlos Valder do Nascimento. São Paulo: Saraiva, 2010.

ARENDT, Hannah. Origens do Totalitarismo. São Paulo: Cia. das Letras, 1989.

BARCElloS, Ana Paula. Curso de Direito Constitucional, 2. ed. São Paulo: Saraiva, 2019.

BOBBIO, Norberto. A era dos Direitos. Tradução Carlos Nelson Coutinho, 11. ed. Rio de Janeiro: Campus, 1992.

COMPARATO, Fábio Konder. A Afirmação Histórica dos Direitos Humanos, 7. ed. Rev. e atual. São Paulo: Saraiva, 2010.

\section{RaQuel Torcani Carmona}

Advogada. Mestranda em Direitos Coletivos e Difusos pela Pontificia Universidade Católica de São Paulo-PUCSP. Especialista em Direito Educacional pela UNISAL. raquel@, semesp.org.br

Submetido em: 29-8-2020

Aceito em: $31-8-2020$ 